Jaramillo-Ferro, J.E. (2017). Movilización de los corteros de caña de azúcar en el Valle del Cauca, huellas y despliegues de una acción colectiva. Revista de Antropología y Sociología: VIRAJES, 19 (2), 93-114. DOI: 10.17151/rasv.2017.19.2.6

\title{
MOVILIZACIÓN DE LOS CORTEROS DE CAÑA DE AZÚCAR EN EL VALLE DEL CAUCA, HUELLAS Y DESPLIEGUES DE UNA ACCIÓN COLECTIVA
}

JHON EDIER JARAMILLO FERRO*

Recibido: 27 de abril de 2017

Aprobado:20 de julio de 2017

Artículo de Reflexión

\footnotetext{
* Profesional en Estudios Políticos y Resolución de Conflictos, Universidad del Valle, Docente de facultad de Ciencias Sociales, humanidades y Teología de la Universidad Católica de Manizales, Magister en Educación y desarrollo Humano Universidad Manizales CINDE. jejaramillo@ucm.edu.co () ORCID: 0000-0002-1491-1230
} 


\title{
Resumen
}

Objetivo. Identificar cómo la movilización de los corteros de caña de azúcar, en 2008, interfirió en la transformación y creación de los sujetos políticos de los actores de la misma; aproximándonos a un entendimiento de los protagonistas del paro dentro de sus entornos, saberes, demandas, relaciones entre sí, el papel de su familia y su historia laboral, permitiendo determinar algunos rasgos de interpretación. Metodología. Para ello privilegiaremos un enfoque crítico, concibiendo la movilización política como el escenario que se configura a partir de aquellas acciones que buscan romper la inercia de las relaciones de poder y cambiar el lugar de subordinación que históricamente se ha asignado a algunas comunidades dentro de una determinada organización social. Resultados. La idea era comprender la movilización de los corteros de caña de azúcar a través del despliegue de la misma en sus dinámicas, realizaciones y propuestas que dejan huellas materiales y simbólicas develando a lo largo de esta investigación "otras formas de vida", otros sentires emocionales, otras dinámicas de relacionamiento. Conclusión. Nos aproximamos a la movilización no solo como espacio que contiene lógicas de subordinación, sino como un escenario para agenciar formas de pensar y vivir diferentes a las del sistema hegemónico, potencializando de esta manera una construcción desde y para los actores mismos alrededor de su construcción como sujetos políticos.

Palabras clave: movilización social y política, identidad política, organización y participación política, acción colectiva.

\section{MOBILIZATION OF SUGAR CANE CUTTERS IN THE VALLE DEL CAUCA, FOOTPRINTS AND DISPLAYS OF A COLLECTIVE ACTION}

\begin{abstract}
Objective: To identify how the mobilization of sugarcane cutters in 2008 interfered in the transformation and creation of the political subjects of its actors, approaching an understanding of the protagonists of the strike within their surroundings, their knowledge, their demands, their relationships with each other, the role of their family and their work history, allowing to determine some features of interpretation. Methodology: For this purpose, a critical approach was privileged, conceiving political mobilization as the scenario that is shaped from those actions that seek to break the inertia of power relations and change the place of subordination that historically has been assigned to some communities within a certain social organization. Results: The idea was to approach the sugarcane cutters mobilization through its unfolding in its dynamics, realizations and proposals that leave material and symbolic traces revealing throughout this investigation "other ways of living", other emotional feelings, and other relationship dynamics.
\end{abstract}

Key words: social and political mobilization, political identity, organization and political participation, collective action. 


\section{Introducción}

L a presente es una reflexión en torno a los componentes teóricos conceptuales de la acción colectiva enmarcados en el paro de corteros de caña de azúcar, en el Valle del Cauca, en 2008; reflexión que se fundamenta en el seguimiento y lectura, desde un enfoque cualitativo, con perspectiva crítica analítica, bajo instrumentos tales como narrativas y entrevistas semiestructuradas.

El Valle del Cauca es una región colombiana reconocida por su riqueza productiva especialmente direccionada al cultivo de caña de azúcar y sus correspondientes derivados como el azúcar, etanol e insumos relacionados con esta materia prima; en el proceso de cultivo los corteros de caña desempeñan un papel muy importante, ya que ellos cortan la caña para ser transportada a sus lugares de transformación; se dimensiona entonces el valor de su labor y el impacto que tiene en el proceso productivo. En 2008, el proceso de contratación para estos trabajadores se modificó por el outsourcing Cooperativas de Trabajo Asociado (CTA) desmejorando significativamente sus condiciones de vida. Este hecho parece indicar un fenómeno de generalización del uso de la intermediación laboral o tercerización en el país, que se orienta a descargar en los mismos trabajadores una parte significativa de los costos de la seguridad social; pero sobre todo porque tiene un efecto de debilitamiento de las organizaciones sindicales al dejar - en términos institucionales - por fuera de la legislación laboral a una masa enorme de asalariados. Por otro lado, encontramos planteamientos de distintos autores(as) en un contexto internacional (Boltanski y Chiapello, 2002; Bauman, 2000; Iranzo y Leite, 2006; De la Garza, 2006) que coinciden en señalar las tendencias en la generalización del uso del outsourcing ${ }^{1}$ en el desarrollo del capitalismo contemporáneo como una de sus características principales; al mismo tiempo, hallamos en el propio sector moderno y capitalista de grandes empresas colombianas el desarrollo de estas tendencias (Arango et al., 1999; Urrea et al., 2000).

Es en este contexto donde se genera la movilización de corteros de caña, de 2008, como una búsqueda del accionar colectivo direccionado a la reivindicación de sus derechos laborales. Permitiéndonos una mirada de la acción colectiva un poco distante del concepto teórico riguroso

\footnotetext{
${ }^{1}$ El término inglés outsourcing, también llamado tercerización o externalización, se refiere al proceso de descentralización de trabajos hacia una firma o empresa externa; la cual, en un principio, no conforma las tareas prioritarias de la actividad económica (producción de un bien o servicio específico) de la empresa en referencia. Ciertamente la experiencia muestra que la tercerización va mucho más allá y puede afectar también a tareas que son necesarias para una empresa ya sean labores calificadas o no calificadas.
} 
y presentando nuevas y esperanzadoras formas de asociación que los contextos determinan.

Dentro del marco de la acción colectiva el proceso invita a pensar las realidades de las comunidades intervinientes que permiten transformar, dimensionar y construir acciones colectivas en un marco conceptual más amplio y que evidencian también el logro de los fines concretos buscados por la misma al constituir sujetos políticos dentro de estas comunidades; sujetos que se dimensionan a sí mismos en un contexto emancipatorio y que permean de manera significativa el marco familiar y social.

De igual forma invita a evaluar el impacto a largo plazo de estas acciones, su continuidad y la vigencia de sus reivindicaciones iniciales, la transformación de las mismas, las nuevas construcciones a partir de estas, la continuidad del liderazgo y el relevo generacional, permitiendo dimensionar el impacto de la acción en el futuro de la comunidad y su apropiación positiva o negativa del mismo.

Mario Alejandro Pérez Rincón, en Deuda social y ambiental del negocio de la caña de azúcar en Colombia, hace una excelente descripción sobre la situación de la caña:

la agroindustria azucarera colombiana ubicada en el valle geográfico del rio Cauca, específicamente en los departamentos de Cauca, Valle del Cauca y Risaralda (ver Figura), posee condiciones geográficas excepcionales para el cultivo de la caña de azúcar: 1.000 metros sobre el nivel del mar, temperatura promedio de 25 grados centígrados con oscilaciones de 12 grados entre el día y la noche, brillo solar superior a las 6 horas diarias, humedad relativa de $76 \%$ y una precipitación promedio de 1.400 milímetros (Asocaña, 2004).

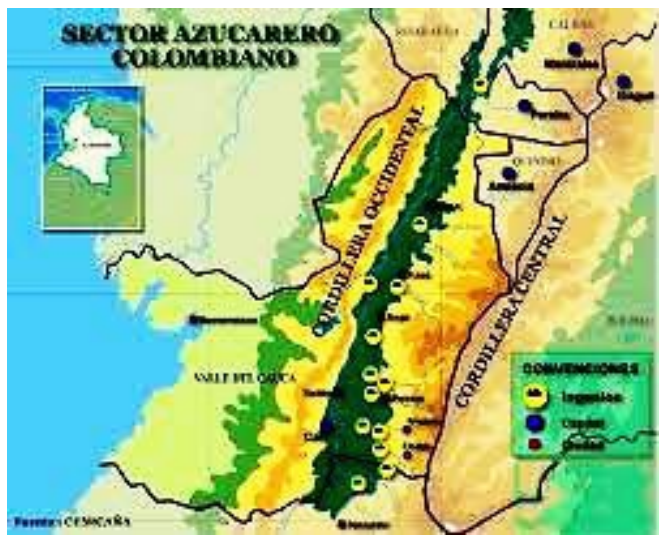


Estas condiciones han generado un espacio ambiental adecuado para el desarrollo de la cañicultura en esta zona del país desde 1867, cuando se construyó el primer trapiche, hasta cuando en las décadas cuarenta y cincuenta del siglo pasado se convirtió en región de mayor producción azucarera del país, alcanzando las 141 mil toneladas, época en que se crearon la mayor parte de los trece (13) ingenios azucareros que operan en Colombia. La industria azucarera se expande en la década del sesenta debido en buena medida al aumento de las exportaciones de azúcar a Estados Unidos que en ese entonces había cancelado sus compras a Cuba (Ramos, 1994). El área sembrada casi se duplica entre los sesenta y los ochenta al pasar de 64 mil a 110 mil hectáreas. A partir de 1990, como resultado de la apertura económica, se acentúa el proceso de especialización de la región hacia el cultivo de la caña de azúcar hasta alcanzar las 203 mil hectáreas sembradas en 2007, que representan la mitad de la disponibilidad de tierra del valle geográfico $[\ldots]$.

[...] Los principales productos elaborados por el sector cañicultor son el azúcar, las mieles y más recientemente el etanol, que le abre un nuevo panorama de negocios al sector impulsado por los altos precios del petróleo resultado de su creciente escasez y la alta demanda energética. En términos de producción azucarera esta pasó de 1,2 a 2,3 millones de toneladas entre 1980 y 2007. Parte de este despegue azucarero se explica por la dinámica exportadora que se incrementó de 280 mil toneladas de azúcar y derivados en 1980 a 1.2 millones en 2005, para luego descender a 716 mil toneladas en 2007 por el desplazamiento del cultivo de caña hacia la producción de etanol. La miel por su parte se ha venido reduciendo al pasar de 321 mil toneladas en 1980 a 250 mil en 2007. Y el nuevo negocio agro combustible, apoyado por las políticas gubernamentales, ha crecido en su producción desde su inicio en 2005 al pasar de 29 millones de litros a 275 millones en 2007 [...].

[...] Estos acontecimientos señalados, permitieron crear y consolidar un gran conglomerado (cluster) en la región — que produce y vende en la actualidad una gran variedad de productos y servicios, compuesto por cerca de 1.200 proveedores de caña de azúcar, 13 ingenios, más de 40 empresas procesadoras de alimentos, bebidas y licores; dos cogeneradoras de energía eléctrica; un productor de papel, tres industrias sucroquímicas, más de 50 grandes proveedores especializados y 100 empresas asociativas de trabajo- que ha constituido la columna vertebral del desarrollo económico y social del departamento del Valle del Cauca (CNP, 2002). (p. 15-17) 
Iniciaré con la descripción del paro como tal y sus características, posteriormente realizaré una reflexión de carácter teórico-conceptual que nos permitirá entender una acción colectiva en el contexto latinoamericano.

\section{Con el despertar, los corteros de caña afilan sus pacoras ${ }^{2}$ en el Valle del Cauca}

La editorial del 25 de septiembre del 2008 del diario el espectador narra que el 15 de septiembre de 2008; a las 4 de la mañana, 10000 corteros de caña vinculados a esta actividad por intermedio de las CTA en 13 ingenios azucareros del valle del río Cauca iniciaron una asamblea permanente con cese de actividades en protesta por las precarias condiciones laborales en que se encontraban, bloqueando la entrada de las plantaciones azucareras.

La decisión de entrar en asamblea permanente con cese de actividades se presentó por la negativa del gremio empresarial de negociar con los trabajadores el pliego único de exigencias, presentado el 14 de julio de 2008, emanado por la gran asamblea realizada en el municipio de Pradera (Valle del Cauca).

Esta negativa estuvo en concordancia con el modelo de contratación que provenía del proceso de flexibilización laboral que originó la Ley 50 de 1990, que puso en marcha el sistema de las CTA para remplazar a otras modalidades de intermediación laboral que funcionaban en la contratación de personal para el corte tales como modelo de contratista particular ${ }^{3}$, las empresas asociativas de trabajo $(E A T)^{4}$ y recientemente el contrato sindical $(\mathrm{CS})^{5}$.

\footnotetext{
${ }^{2}$ Herramienta utilizada por los corteros de caña de azúcar para su oficio.

${ }^{3}$ De conformidad con el artículo 34 del Código de Trabajo, el contratista independiente (o particular) "es un empleador, persona natural o jurídica que contrata la ejecución de una o varias obras o la prestación de servicios en beneficio de terceros, por un precio determinado, asumiendo todos los riesgos, para realizarlos con sus propios medios y con libertad y autonomía técnica y directiva".

${ }^{4}$ Conforme a lo establecido en el artículo 1 de la Ley 10 de 1991, "las Empresas Asociativas de Trabajo son organizaciones económicas productivas, cuyos asociados aportan su capacidad laboral, por tiempo indefinido y algunos además entregan al servicio de la organización una tecnología o destreza, u otros activos necesarios para el cumplimiento de los objetivos de la empresa. Los asociados tienen una relación de carácter típicamente comercial con las empresas asociativas de trabajo. Por tanto, los aportes de carácter laboral no se rigen por las disposiciones del Código Sustantivo del Trabajo, sino por las normas del derecho comercial, por lo cual deberá ser registrada en el Ministerio de Trabajo y Seguridad Social, Subdirección de Trabajo Asociativo e Informal, con la presentación del certificado de existencia y representación, expedido por la Cámara de Comercio y copias auténticas del acta de constitución y los estatutos".

${ }^{5}$ El contrato sindical está regulado por el artículo 482 del Código Sustantivo del Trabajo, de acuerdo con Ricardo Aricapa (2006): "el contrato sindical es una de las tres formas de contratación colectiva consagradas en la legislación, y data de mucho tiempo atrás, casi desde los albores del sindicalismo colombiano. Mediante este tipo de contrato el sindicato pasa a hacer las veces de empleador y presta tal servicio a un tercero, que puede ser la propia empresa en la que opera el sindicato $u$ otras distintas.
} 
Aproximadamente 100 CTA contrataban a más de 9000 personas, liberando a los ingenios azucareros de las responsabilidades que bajo contratación directa deberían asumir, narrado en la editorial del 25 de septiembre del 2008 del diario el espectador el 15 de septiembre de 2008, se dio un primer paro que no mejoró en nada la situación laboral pero que les dejó a los trabajadores un importante legado organizativo de movilización. Entre los meses de mayo y julio de 2005 se generaliza paulatinamente una huelga masiva de corteros de caña en los diferentes ingenios del valle geográfico del río Cauca con bloqueos a la entrada de las distintas empresas. Así, describe el movimiento huelguístico en semana, editorial del 24 de septiembre del 2008 se informa que : en total fueron 62 días de huelga, en 13 ingenios azucareros, por 59 CTA: en INCAUCA, 5; en Pichichi, 6; en Castilla, 5; en La Cabaña, 7; en Providencia, 4; en Central Tumaco, 21; en Manuelita, 9; en Mayagüez, 5. Cerca de 11000 corteros en pie de lucha atrajeron a su movimiento no solo a sus familias sino también a los pobladores de los municipios aledaños, cobijando su gesta a cerca de 100000 personas.

Las peticiones eran las mismas: cese de la contratación a través de las CTA, los contratistas y el contratismo sindical; aumento del precio por tonelada de caña cortada; no al robo descarado con el pretexto de la "materia extraña"; compensaciones para el pago de prestaciones sociales y aportes a la seguridad y a la salud, dotaciones y elementos de trabajo, y unas cuantas reivindicaciones para la dignificación moral de los obreros tales como el acceso a la recreación y el descanso.

Los acuerdos alcanzados: incremento del $6 \%$ en las tarifas de corte, incluyendo las compensaciones por prestaciones sociales y aportes a la seguridad social en los porcentajes de ley; eliminación del concepto de "materia extraña", dotaciones y elementos de trabajo como lo establece la ley; obligatoriedad en el pago de la seguridad social, eventos de integración con la familia del trabajador; desmonte de las actuales cooperativas, incluyendo el contrato sindical; financiación de cursos de cooperativismo, auditoria periódica a las básculas y todo el proceso de pesaje; préstamos para adquirir elementos de oficina para las cooperativas, que supuestamente quedaron administradas por los trabajadores, así como el total del corte.

En resumen, aunque lograron algunas mejoras en la venta de la fuerza de trabajo, el objetivo del enganche directo a las empresas sigue siendo el problema fundamental; reivindicación a la cual los corteros no

Funciona de manera similar a las cooperativas, mediante oferta mercantil que el sindicato le presenta a la empresa, mientras con cada cortero firma un contrato de pago por tajos cortados. Éstos por su parte deben afiliarse al sindicato y aportar la cuota sindical, sólo que la convención colectiva que el sindicato pacta con la empresa no es aplicable a ellos. Son sindicalizados pero no gozan de todos los derechos Sindicales" (p. 11). 
han renunciado como puede apreciarse en declaración de 5 de octubre: "no renunciamos a reclamar la contratación directa y reiteramos nuestra disposición de lucha para lograrla" (palabras de un cortero entrevistado).

Hoy, pese a los esfuerzos generados en el 2005 y con mayor impacto y resultados en el 2008, el proceso de reivindicación de los derechos laborales y la lucha continúan; la exigencia de los corteros a través de su sindicato nacional (SINALCORTEROS) se fundamenta en la contratación directa, la estabilidad laboral y negociaciones colectivas. Por su parte el Ministerio de Protección Social, en un tono más bien cínico, ha manifestado que las CTA son entidades independientes y como tal los asociados no pueden - entre otras cosas- ejercer el derecho de negociación colectiva ni votar la huelga porque como asociado, y al mismo tiempo dueño de la empresa, no existe posibilidad legal de presentar un pliego de peticiones: "los asociados de una cooperativa no pueden ejercer el derecho de negociación colectiva, ni votar la huelga" narrado en la editorial del 25 de septiembre del 2008 del diario el espectador del 15 de septiembre de 2008.

En asamblea permanente manifestaron ser trabajadores de siembra, campo, cosecha y fábrica, al servicio de la industria azucarera, por lo cual exigen condiciones de trabajo dignas: "porque no podemos seguir esclavizados bajo el sistema de contratistas y cooperativas con más de 14 horas de trabajo diarias para recibir un salario miserable que no alcanza los 400 mil pesos mensuales" (palabras de un cortero entrevistado); dijeron los corteros al declararse en paro.

Para fortalecer la investigación de la cual se deriva el presente artículo, el investigador acompañó distintos grupos de corteros ubicados en el Valle del río Cauca en la construcción de sus procesos colectivos y las distintas acciones que como comunidad realizaron en pro de sus causas y por su subsistencia durante el tiempo de paro; durante este período de acompañamiento el investigador tuvo la oportunidad de entrevistar a los líderes y a otros miembros del colectivo, lo que le permite soportar las interpretaciones derivadas de la investigación; igualmente participó en la creación de vídeos noticiosos de carácter local.

El gobierno nacional y los empresarios optaron por solucionar este conflicto laboral haciendo uso de la fuerza, y estigmatizando la movilización de los corteros, argumentado que la huelga fue promovida por una minoría de trabajadores pertenecientes a las cooperativas quienes impidieron que la mayoría pudiesen ingresar a los ingenios a continuar con la producción constituyendo un bloqueo inaceptable. El ministro de Agricultura de ese entonces, Andrés Felipe Arias, dijo que tras la huelga se escondían "fuerzas oscuras" y que la policía y el ejército estaban informados de la situación, en semana, editorial del 24 de septiembre del 2008; lo que les llevó a utilizar 
todos los mecanismos necesarios para volver a la normalidad. Términos muy parecidos utilizó el presidente del gremio azucarero, correspondiente al año 2008, ASOCAÑA, Luis Fernando Londoño Capurro el cual no vio fuerzas 'oscuras' sino 'extrañas' en el movimiento huelguista.

Debido a la petición realizada por los corteros de caña a la Comisión Séptima del Senado para que interviniera en el conflicto laboral originado por el modelo de contratación indirecta el senador Alexander López Maya, los comités locales de audiencia (conformados por los trabajadores), la Corporación Humanidad Maestra Vida, SINALTRAINAL, SINTRACORTEROS y SINTRAICAÑAZUCOL, convocaron para el 14 de junio de 2008 en el municipio de Pradera a la audiencia pública sobre agrocombustibles y condiciones laborales del Valle del Cauca.

Cerca de 7000 trabajadores corteros de caña, con sus familias, se reunieron con diversos sectores sociales en el parque central del municipio de Pradera para denunciar los atropellos y condiciones de trabajo inhumanas en las que se encontraban. La audiencia fue instalada por los representantes de los corteros y el senador López Maya, contando también con la participación de miembros de la bancada del Polo Democrático Alternativo como la senadora Gloria Inés Ramírez y el senador Jorge Enrique Robledo. Igualmente participaron la representante a la cámara por las comunidades afrodescendientes María Isabel Urrutia e importantes organizaciones sociales de la región como la Asociación de Cabildos Indígenas del Norte del Cauca (ACIN), el Proceso de Comunidad Afrodescendientes (PCN), la Asociación de Trabajadores del Puerto de Buenaventura, la Liga de Usuarios de Servicios Públicos, comités de derechos humanos, estudiantes universitarios y miembros de diferentes grupos sindicales.

Durante la asamblea se escucharon los testimonios de los trabajadores corteros de caña que denunciaron ignominiosas condiciones laborales, así como las irregularidades realizadas por los contratistas y los ingenios.

Los trabajadores no contaban con seguridad social en un trabajo de alto riesgo en el que muchas veces quedan incapacitados a temprana edad y no tenían ningún control sobre las básculas de pesaje de la caña que cortaban, por lo que no sabían si estaban recibiendo el pago correspondiente a su trabajo diario. Estos eran sometidos a un modelo de contratación que afectaba -y sigue afectando- gravemente sus derechos laborales bajo la figura de las CTA donde debían asumir el pago de sus prestaciones y seguridad social. Además recibían un trato displicente por parte de las empresas prestadoras de salud, administradoras de riesgos profesionales y de pensiones de la región, que de manera descarada se negaban - y aún lo hacen- a reconocer como enfermedades laborales a las afecciones que sobre la salud de los trabajadores producen las extenuantes jornadas de 
trabajo; las cuales, desde entonces y hasta hoy, pueden ser de 14 y 16 horas diarias en el corte de caña. Tampoco les fueron reconocidas las pensiones de invalidez, en tanto que por esta misma razón quedan paralizados debido a recurrentes enfermedades articulares y musculares producidas por el constante ejercicio del corte.

Los corteros de caña de azúcar, y algunas esposas presentes en la "Gran Audiencia Pública", manifestaron:

producen combustible, producen papel, alcohol, producen energía, gas y donde está la plata de esos productos no nos hemos beneficiado en nada nosotros los corteros de caña. Estamos peor que nunca... Aquí nos hicieron creer que las famosas cooperativas tenían muchos dividendos para nosotros y que nos sintiéramos orgullosos de ser empresarios pero somos unos empresarios llenos de deudas, unos empresarios sometidos al hambre y la miseria. Cabe decir que somos un rico sin cinco; eso es lo que somos en las cooperativas, porque todo el poder, toda la obligación de los oligarcas no las cargaron a las costillas de los pobres. Nosotros tenemos que pagar una seguridad al ciento por ciento, tenemos que pagar el trasporte para ir a cortar caña, tenemos que pagar un impuesto al alcalde para que nos deje cortar caña; ¿a dónde han visto ustedes una injusticia de esas?

Vengo a reclamar las reivindicaciones sociales, las reivindicaciones laborales, las reivindicaciones en salud, que el gobierno a través de decretos infames, nos ha desconocido y nos ha arrebatado las conquistas que nos ha costado sangre, nos ha costado perdida de compañeros, destierros y todo eso para arrebatarnos las conquistas que han tenido los trabajadores por décadas en la historia laboral de Colombia. Reclamo hoy aquí la presencia del ministro de agricultura que al parecer le dio miedo venir a confrontar la verdad, porque todos ustedes conocen lo que el por el canal del congreso manifiesta, que nosotros somos ricos, que no necesitamos, que nos estamos ganando más de un millón de pesos y hoy le dio miedo y desde aquí le digo que es un mentiroso. Le reclamamos que por qué no hizo presencia hoy aquí, a decirnos de frente y tratarnos de mentirosos como le dice a los compañeros cuando están en la plenaria. Que vivan corteros de caña todos unidos. (Nuestro Magazín, 2008) ${ }^{6}$

\footnotetext{
${ }^{6}$ Las opiniones aquí plasmadas son producto de la investigación realizada por el autor, las cuales para generar difusión pública de las acciones realizadas por los corteros se difundieron en un programa televisivo producto derivado de la misma investigación.
} 
Sumado a lo anterior, las compañeras de los corteros de caña de azúcar se pronunciaron dirigiéndose a la audiencia en nombre de todas aquellas personas que como ellas deben asumir una fuerte carga de trabajo familiar; levantándose, diariamente, muy temprano en la mañana para preparar los escasos alimentos que sus esposos deben llevar para soportar la larga y dura jornada laboral que injustamente es remunerada con un salario que no les alcanza ni siquiera para que sus hijos puedan comer bien —o ni saborear un helado en un parque cualquier domingo o día de fiesta-.

A veces se lleva un huevo, una libra de arroz, a veces se llevan tres bananos cocidos porque no hay más que echarle, la situación de los corteros de caña es dura.

Es duro decirle a un hijo no tengo que darle de comer, es muy duro. Es demasiado triste tener que decirle a un hijo, "mijo no hay". ni siquiera una agua panela para mandarlo a estudiar, yo me levanto a las tres de la mañana a despachar a mi esposo, se va a las cinco de la mañana y no me vuelvo a acostar hasta las diez, once de la noche, porque son las ocho de la noche y mi esposo no ha llegado a la casa... acabando de trabajar duro, fuerte con un sueldo miserable y cuando llega la quincena qué dolor, qué tristeza, mi esposo con un sueldo miserable de ciento ochenta mil pesos o doscientos mil pesos para quince días. (Nuestro Magazín, 2008)

El panorama en ese entonces se visualizaba desolador, tal como lo manifestaban las mujeres compañeras de los corteros por medio de entrevistas y vídeos utilizados en la investigación, pues no quedaba duda de que el atropello al cual fueron sometidos los corteros por parte de los ingenios azucareros - bajo la complacencia del Estado a través de la ley de flexibilización laboral - era el que impulsaba en gran medida el ejercicio de movilización de este gremio.

De esta manera los industriales de la caña recurrieron a múltiples argumentos en el afán de deslegitimar la movilización, por ejemplo: que la huelga era promovida por una minoría de trabajadores pertenecientes a las cooperativas que impedían que la mayoría —en esencia aquellos que sí gozaban de contrataciones directas y condiciones labores aceptables, personal de planta - pudiesen ingresar a los ingenios a continuar con la producción, lo cual constituía un bloqueo inaceptable, dejando ver entre líneas la violación del derecho al trabajo.

Por otro lado, en junio de 2008, la Procuraduría General de la Nación frente a los corteros- anunció que investigaría su penosa situación laboral y tomaría cartas en el asunto. Tres años antes, en 2005, por los mismos motivos, 
se llegó a un primer paro que no mejoro para nada la situación. Poco había cambiado desde entonces el modelo de contratación, base de la disputa del mismo. Aproximadamente 100 cooperativas de trabajo asociado contratan a más de 9000 personas y liberan a los ingenios azucareros de las responsabilidades que bajo contratación directa deberían asumir. Hasta el momento no existe un estatuto legal que obligue a los ingenios a contratar directamente; por el contrario existe una ley de flexibilización laboral que establece un proceso de intermediación laboral, consagrado en la Ley 50 de 1990, dejando una alternativa para los corteros: el paro indefinido como acción colectiva.

\section{Huellas y despliegues de una acción colectiva}

Las relaciones de carácter comunitario tienen una enorme fuerza y que es en el seno de éstas relaciones donde se forjan movimientos e insurrecciones. (Zibechi, 2007, p. 35)

La acción colectiva se entiende como el sustrato mismo de lo social en cuanto implica la coordinación de la acción de un individuo con otros para el logro de sus fines vitales más inmediatos. Imaginarnos una sociedad conformada por individuos aislados e incomunicados entre sí sería incompatible con la evolución histórica del ser humano, ya que las sociedades de hoy se caracterizan por el incremento de la complejidad y la densidad en los flujos comunicativos y redes de trabajo y cooperación vinculados a los mismos.

Charles Tilly (1998) establece la siguiente tipología al referirse a la acción colectiva:

La acción competitiva: un grupo que define a otro grupo como enemigo o rival y que ataca sus recursos, generando dos tipos de encuentros violentos: si el grupo es pequeño, informal o compuesto por miembros hereditarios, podemos llamar a las acciones primitivas. Si los grupos implicados son relativamente grandes, formalmente organizados y especializados, podemos llamarlos acciones de grupo de interés.

La acción proactiva: es realizada por grupos que reivindican un derecho a un bien sobre el que no ejercían previamente un control y otro grupo que resiste esa reivindicación: el grupo que realiza nuevas demandas es relativamente grande, formalmente organizado y especializado, la confrontación violenta que surge de esta acción colectiva es denominada como moderna.

La acción reactiva: los grupos o sus agentes reivindican un bien que en ese momento fue revocado o disfrutado poco, dando lugar a dos clases de violencia colectiva: la violencia reaccionaria y la violencia defensiva. 
Tilly (1990) tipifica una acción colectiva como contenciosa e identificada en acciones que llevan a cabo partidos políticos y grupos de interés que son ajenos a las instituciones y surgen desde sus valores, creencias e intereses no aceptados.

Como podemos ver, la teoría de la acción colectiva a través de los años se ha constituido desde diferentes enfoques teóricos que no solo definen su entramado teórico sino también la forma de abordar el objeto de estudio. Como, por ejemplo: el comportamiento colectivo; la elección racional; la movilización de recursos y la perspectiva de los actores.

Dentro del comportamiento político los teóricos de la acción colectiva se definen a partir del cuestionamiento y respuesta al mismo, en cómo y por qué los individuos deciden actuar de manera unida en aras de un bien común.

McCarthy (1999) plantea que son las condiciones de la sociedad y la estructura de la misma, bajo la inconformidad, las que motivan a los individuos a unirse en una acción coordinada en contra de ellas de un modo espontáneo o desde un movimiento social. Se define como una ruptura de un sistema establecido, por lo que algunos ven la acción colectiva como un mecanismo para restituir el orden perdido y otros ven en ella una fuerza de transformación y reestructuración (McCarthy, 1999).

En este sentido este grupo de corteros interpretaba a sus empleadores como sus contrarios ante las evidentes diferencias derivadas de la contratación por tercerización donde sus derechos laborales fueron vulnerados, menguando las condiciones mínimas del buen vivir de los trabajadores contratados por esta nueva forma de contratación.

En aras de aclarar el contexto del presente artículo, es pertinente iniciar con un reconocimiento general de lo que hasta este momento se ha abordado en torno a los movimientos sociales. A partir de la década del 60 se pueden percibir desarrollos significativos en investigaciones de corte empírico sobre los movimientos sociales en Europa y Estados Unidos. Es posible identificar que este se desarrolló en torno a dos escenarios epistémicos interesantes: el primero se caracteriza por utilizar el despliegue de estructuras y modelos de análisis, respondiendo a un escenario específico y focalizado donde el análisis estratégico y el aspecto racional configuran la movilización de los recursos y la estructura organizacional para los movimientos sociales (Melucci, 1994). El segundo surge bajo la importancia de entender los valores y las demandas del cambio social, configurando un escenario que se entiende a través del concepto de "nuevos movimientos sociales". Estas dos perspectivas, a lo largo de las investigaciones, manifestaron oposiciones de corte conceptual; siempre alimentando lo que hoy podemos entender por movimientos sociales, vistos desde una parte del mundo en especial (Tilly, 1993; Tarrow, 1997; McAdam, , 1999). 
Las investigaciones, un poco más tardías, sobre movimientos sociales en América Latina, recogen un tenue eco de las posturas epistémicas desarrolladas en Europa y Estados Unidos hasta los años 80; toda vez que al momento de analizar las particularidades de los movimientos sociales en América Latina, y específicamente en nuestro caso el Valle del Cauca (Colombia), se hace necesario utilizar producciones científicas propias del Cono Sur para comprender la movilización de los corteros de caña de azúcar a través del despliegue de la misma en sus dinámicas, realizaciones y propuestas que dejan huellas materiales y simbólicas. Se busca develar a lo largo de esta investigación "otras formas de vida", otros sentires emocionales, otras dinámicas de relacionamiento que distan del modelo hegemónico establecido permeado por la mecanización y la mercantilización del trabajo y por lo tanto de la mano de obra (Zibechi, 2008).

De esta manera la investigación privilegia un enfoque de interés emancipatorio o critico-social, concibiendo la movilización política como el escenario que se configura a partir de aquellas acciones que buscan romper la inercia de las relaciones de poder y cambiar el lugar de subordinación que históricamente se ha asignado a algunas comunidades dentro de una determinada organización social (Vasco, 1990); aproximándonos a la movilización no solo como espacio que contiene lógicas de subordinación sino como un escenario para agenciar formas de pensar y vivir diferentes a las del sistema hegemónico, potencializando de este modo una construcción desde y para los actores mismos alrededor de un sentido de pertinencia e identidad política.

Tradicionalmente se puede observar que los sectores populares, para lograr superar las dificultades que enfrentan cotidianamente, se unen y trabajan colectivamente. Siendo este uno de los factores aglutinadores de las demandas comunes que tienen todos(as) los(as) que sufren las mismas privaciones y enfrentan idénticos problemas. La convicción de que no se puede mejorar la situación de desigualdad y subordinación mediante iniciativas individuales sino solo mediante la acción colectiva, hace que predomine el nosotros sobre el yo.

Para poder comprender esta idea en el estudio realizado, es necesario localizarla en el comportamiento político. Para ello utilizaremos conceptos a los que hacíamos referencia al inicio de este texto, en donde los teóricos definen la acción colectiva a partir del cuestionamiento y respuesta al mismo comportamiento político del cómo y porqué los individuos deciden actuar de manera unida en aras de un bien común. Por lo tanto se define como una ruptura de un sistema establecido y/o el esfuerzo por mantenerlo, el punto es que algunos ven a la acción colectiva como un mecanismo para 
restituir el orden perdido y otros ven en ella una fuerza de transformación y reestructuración.

Otros autores cuestionan el carácter colectivo, no de la acción sino de la elección de actuar; tal como lo propone, Olson (1992), en su teoría de grupos, afirmando que:

los individuos son sujetos racionales cuyas decisiones de actuar estarán antecedidas de un cálculo de costo-beneficio a partir de sus propios intereses; la mera conciencia del interés común no será entonces motivo suficiente para formar parte de una acción colectiva, a menos que los beneficios de ello sean iguales o superiores a los obtenidos de manera individual, o bien exista una fuerza coercitiva u otro mecanismo de incitación que involucre a los sujetos. (p. 372)

Ahora bien, y en torno a la reflexión propia que pasa directamente por la focalización de la movilización de los corteros de caña de azúcar del Valle del Cauca en 2008, decimos que dicha participación social y política de un sector social puede ser comprendida a través del marco de los denominados "nuevos movimientos sociales". Sin embargo, y como ya lo mencionamos, se pretende analizar este movimiento social como un escenario complejo propio de toda la acción colectiva al incorporar nuevas líneas de interpretación; ya que para la acción colectiva estas resultan fundamentales para dar cuenta del rol de gestores que ocuparon los corteros en los procesos de transformación política y cultural, apuntando a una formación social determinada. Los movimientos sociales son el escenario donde surgen y toman forma nuevos temas como discursos y agendas públicas, además de propiciar el espacio de sociabilidad y recreación de la misma sociedad; por otro lado, prefiguran e incluso cristalizan nuevas formas de comportamiento individual y colectivo. A partir de esta perspectiva los movimientos sociales, dentro de las colectividades que integran individuos y organizaciones, pretenden ser "agentes colectivos movilizadores" (Riechmann y Fernández, 1994) de los procesos que inciden en la creación y transformación del espacio público.

Las circunstancias históricas de la época en la cual se inscriben los movimientos sociales son transformadoras de los mismos debido a que estos no solo son un reflejo de las condiciones materiales que existen en los individuos que los conforman, sino que también en ellos influye el estado anímico y cultural de la época.

De esta manera es necesario entender los movimientos sociales dentro de un espacio-tiempo complejo de la historia y las ideas en las que confluyan realidades cotidianas. 
Un movimiento social puede ser definido como:

agente colectivo movilizador, que persigue el objetivo de provocar, impedir o anular un cambio social fundamental, obrando para ello con cierta continuidad, un alto nivel de integración simbólica y un nivel bajo de especificación de roles y valiéndose de formas de acción y organización variables. (Riechmann y Fernández, 1994, p. 58)

Siendo esta definición la que recoge una mayor parte de los elementos que se acomoden al entendimiento de nuestro objeto de estudio.

De lo anterior se puede inferir que en estos procesos opera una dinámica de trabajo colectivo a la que se acude de forma permanente para solucionar las pequeñas y grandes dificultades ya sea en la vida cotidiana o en las grandes acciones políticas. Esta dinámica de trabajo se moldea o reinventa a partir de las relaciones mismas.

Es precisamente desde esta idea de donde desarrollamos un elemento teórico fundamental para nuestro interés investigativo, en términos de apreciación y postura frente a la movilización de los corteros, entendiendo que:

la comunidad no es una institución, ni una organización en términos abstractos y generales, sino una forma que adoptan los vínculos entre las personas; la comunidad se hace en las relaciones que permiten agenciar colectivamente los recursos necesarios para vivir. La capacidad de acción de los sectores populares reside en la comunidad, en el conjunto de relaciones sociales, que configuran formas de producción, de organización, representación, significación y autoridad política diferentes a la de la sociedad dominante. Estas relaciones comunitarias representan la movilización societal que le da forma a los movimientos anti sistémicos o a una sociedad en movimiento. (Zibechi, 2006, p. 96)

Sin embargo, la comunidad no se reduce a un vínculo instrumental para lograr fines individuales. Retomando a Max Weber (2002) el concepto de comunidad es opuesto al de asociación: mientras que esta última se asienta en acuerdos racionales de interés, la comunidad es una relación subjetiva entre quienes constituyen un todo. Siendo la solidaridad un elemento constitutivo de las relaciones comunitarias y la representación de las asociaciones destinadas a conseguir fines.

La teoría de la acción colectiva, vista desde las posturas heredadas de las investigaciones realizadas en Europa y Estados Unidos al aproximarse a las estructuras, fines e identidades de la movilización social, concibe a 
la comunidad y a los movimientos sociales como instituciones y no como relaciones; desconociendo que en la vida cotidiana las relaciones de vecindad, amistad, compañerismo, compadrazgo, familia, son organizaciones de la misma importancia que el sindicato, el partido y hasta el propio Estado.

En el imaginario dominante se entiende por organización lo instituido; y esto suele ser aquellas relaciones de carácter jerárquico, visibles y claramente identificables. Las relaciones pactadas, codificadas a través de acuerdos formales, suelen ser más importantes en la cultura occidental que las fidelidades tejidas por vínculos afectivos. En resumidas cuentas, la asociación (donde los vínculos de racionalidad convierten a las personas en medio para conseguir fines) suele ser considerada más importante que la comunidad (tejida con base en relaciones subjetivas en las que los fines son las personas). La realidad indica lo contrario, que las relaciones de carácter comunitario tienen una enorme fuerza y que es en el seno de esas relaciones donde se forjan movimientos e insurrecciones (Zibechi, 2006).

Las relaciones sociales cotidianas que buscan romper los mecanismos de dominación y control social son las acciones de lucha y resistencia que han permitido que mujeres, hombres, jóvenes y niños desplieguen su capacidad de ser comunidad, de crear comunidad, de actuar como comunidad y de resistir; estas formas de resistencia, emergen en los discursos de los corteros durante la movilización de 2008.

Observando estas características de la movilización de los corteros, es posible afirmar que esta es protagonizada por organizaciones comunitarias cuya reivindicación se centra en las reclamaciones de bienestar alrededor de la condición laboral. Estas reivindicaciones potencializan las luchas que se dan en formas organizativas de acción colectiva que no se encuentran inscritas en las matrices tradicionales sobre "la política" y "lo social".

Esta acción colectiva ha emergido, más bien, desde prácticas comunitarias que asumen la diversidad de la experiencia humana como fundamento para las luchas por un mundo mejor. De este modo desafían tanto al statu quo como al estudio mismo de los movimientos sociales. Por tanto, más que interpretar el escenario a través de perspectivas estructurales, es necesario visibilizar las acciones de resistencia y emancipatorias que asumen estas luchas sociales en la práctica misma de la resistencia contra el capitalismo neoliberal.

El sociólogo portugués Boaventura de Sousa Santos (2009) desarrolla esta visión en términos de subvertir al statu quo por medio de la convicción de que lo ausente tiene su propia existencia y por lo tanto puede ser recuperado a través deunainvestigaciónalternativaqueselibera delpoder-saberdominante. Afirma sobre la existencia de regímenes de conocimiento alternativos, prácticas políticas subalternas y experiencias de vida contrahegemónicas que 
se desarrollan en las periferias del poder y que desafían al statu quo. Sobre la base de sus críticas a la ciencia moderna occidental, propone una teoría social que busca recuperar las experiencias desperdiciadas y los conocimientos silenciados a partir de una nueva racionalidad que valore las diferentes formas de vida que existen en el mundo.

Dentro de este esfuerzo de producir un conocimiento desde y para la movilización social, que identifique la construcción de un sujeto político que se involucre a partir de la movilización política y que sea un resultado de la misma movilización, es pertinente resaltar una caracterización hecha por Zibechi (2008) que resulta útil para el presente análisis: (i) es necesario tener en cuenta el arraigo territorial de los movimientos, a saber, el espacio en el que se reproduce ontológica y materialmente la comunidad; (ii) la autonomía emerge como forma de organización que implica la desconfianza de las prácticas clientelares del Estado y de los partidos políticos; (iii) se da una revalorización cultural de sus identidades, lo cual implica el desbordamiento de categorías eurocentradas como la ciudadanía; (iv) se da la apropiación y descolonización de saberes, representada en la formación de sus propios cuadros y corrientes intelectuales; (v) es importante tener en cuenta el papel de las mujeres en la creación de otras lógicas organizacionales; (vi) no puede estar por fuera del análisis, la relación con la naturaleza; (vii) se retoman las formas autoafirmativas de reapropiación de espacios públicos representadas en la toma de ciudades, asentamientos y lugares de memoria.

El escritor plantea que es en "el sótano" de nuestras sociedades donde se ha aprendido a vivir a pesar del capitalismo, incluso a construir modos de vida más allá del modelo de civilización dominante. A partir de la politización de la diferencia, y la conquista de territorios periféricos, se han creado prácticas políticas y relaciones sociales basadas en valores no capitalistas como la solidaridad y la reciprocidad. En este sentido Zibechi, más que movimientos sociales, ve "sociedades en movimiento" en las que son las relaciones sociales mismas las que son conmovidas y reconstruidas por los(as) actores sociales. "Los mecanismos de los sectores populares para lograr las reivindicaciones de sus movilizaciones son las redes sumergidas en la sociabilidad cotidiana de los de abajo, en general invisible para el de arriba" (Zibechi, 2006, p. 325).

La movilización de los sectores populares constituye un vasto movimiento social y político de autoafirmación que no busca institucionalizarse como movimiento, por lo que busca reivindicar una condición de vida digna en términos laborales; es el sentir que hace parte de una sociedad inclusiva y creciente con las políticas que aseguran este crecimiento y dignidad humana. 
Para comprender los movimientos sociales como sociedades en movimiento no basta estudiar sus estructuras, fines e identidad sino ante todo sus acciones que son, además, por lo general, acciones contra lo que se les impone, acciones de lucha y resistencia.

La movilización no presenta su propuesta como un programa definido y delimitado, sino como un trabajo colectivo que nos permite abrir múltiples puertas y ventanas para continuar modificando las relaciones entre las personas; para que entre sí entablen otro tipo de vínculos con las cosas que, a fin de cuentas, son la manera profunda de autoemancipación. Esto es, modificar-trastocar-transformar el mundo social.

Teniendo en cuenta lo que hasta ahora hemos planteado, podemos fortalecer nuestra tesis hablando de la subjetividad como esa comprensión particular que construye el individuo y en la que involucra todos los aspectos fundamentales que le permiten ser: su historia, sus experiencias, su perspectiva de vida entre otros. Todo esto entre el mismo sujeto y su relación con los otros, pues está claro que nuestras subjetividades no devienen de la nada sino de las relaciones y procesos de socialización en los que estamos inmersos. Es poder reconocernos a nosotros mismos en toda nuestra dimensión humana, descubrirnos, conocernos, redireccionarnos, otorgar sentido a las experiencias que configuran nuestras biografías, aprender a ser uno mismo desde "el cómo somos y estamos en el mundo" (Alvarado et al., 2012, p. 27).

La subjetividad se entiende desde esa postura personal que afecta o impacta al otro y que se devuelve en la construcción que otro hace de lo que recibe al consolidar su propia subjetividad, creando una red articulada de sujetos en una comunidad. Mi subjetividad me distingue del resto de individuos y le da sentido a mi existencia, orienta mis valoraciones, mi lenguaje, mis acciones. La subjetividad nunca termina de ser algo inasible porque jamás tiene una forma definitiva o acabada; se redimensiona y toma nuevos significados a partir de cada una de las vivencias, acontecimientos y experiencias que imprimen sentido a lo que soy o, mejor aún, a lo que estoy siendo en un presente permanente cargado de historia y de expectativas de futuro.

Alvarado et al. (2012) nos hablan de dos aspectos de la subjetividad, referenciando a Zemelman, cuando proponen como hipótesis:

la definición de factores encubridores del verdadero repliegamiento del sujeto sobre sí mismo y sobre sus relaciones primarias: la ignorancia, el miedo, la apatía y el aislamiento. Estos son factores que bloquean, que atrapan al yo, que le impiden pensar y actuar, tener posturas claras y voluntad real de construcción con otros, que 
configuran subjetividades pasivas, conformistas, acríticas, no lúcidas, es decir, en términos de Agnes Heller (citada por Zemelman, 2004), subjetividades subalternas, subjetividades sin un sujeto real que las habite. (p. 29)

La interpretación que se puede derivar de este texto es que dentro de la constitución de subjetividad en los sujetos hay una activa que le permite participar, construir, reconocerse a sí mismo y al otro; así como hay una subjetividad pasiva que se manifiesta por los temores, la apatía, el aislamiento de un sujeto impidiéndole participar y llevándolo a conformarse con esa realidad de su contexto sin permitirse una construcción propia, con y teniendo en cuenta al otro; siendo precisamente esta última situación la que debe ser atendida con especial interés en los procesos formativos formales o no formales involucrados en los contextos de socialización, de comunidad, devolviéndole su capacidad de pensamiento crítico y de construir conocimiento propio.

Puede concluirse, entonces, que la subjetividad es la interpretación personal que tiene un sujeto de sí mismo en la que integra todo lo que es como persona: no solo sus fortalezas, habilidades, actitudes, sino también sus emociones, sueños; como parte de un contexto desde su historia, tradiciones, cultura, experiencias de vida; haciendo una construcción integral de él como un sujeto en un entorno social dado que toda esta construcción de sí mismo la hace con el otro, para el otro, por el otro. La subjetividad, aun cuando es una construcción de individualidad, trasciende a esta para hacerla parte de un contexto social determinado en el que el sujeto se referencia con el otro entendiendo que no puede ser sin pensar en el otro; que su propia construcción está determinada por la construcción del otro, así como el mismo impacta la subjetividad de los otros. Recurriendo a los diversos planteamientos de teóricos en la materia; la subjetividad hace parte de la trama histórica de la realidad y por consiguiente el discurso del individuo está sujeto a esa interpretación particular de "la verdad" que cada uno realiza de un hecho, pero que articulada con "la verdad" del otro construye la trama histórica en la que un grupo vive su cotidianidad.

En este orden de ideas podemos decir, a manera de conclusión, que en el camino de la movilización se hace posible entender la construcción de los sujetos y la formación de la comunidad. Es decir no se consolidan sujetos estáticos y organizaciones institucionalizadas, 'estructuras', 'partidos', que solo después de existir como tales luchan sino que de manera múltiple y polifónica sellevan adelanteluchas que engendran, después, explícitamente, sujetos colectivos. 
De este modo la movilización de los corteros de caña va más allá de la resistencia o de la emergencia de un movimiento social, si es que de esta forma lo queremos plantear, ya que este no se ha limitado a contener las lógicas de subordinación; más bien este proceso organizativo y acción colectiva generó, en muchos de sus participantes, nuevas formas de pensar y vivir diferentes a la del sistema hegemónico configurando formas de pensar en contraposición a dicho sistema y transformando a la vez sus formas de relacionarse, de vivir en contexto, de empoderarse de su condición de sujeto político, de entender su lugar en un mundo globalizado, adoptando y utilizando herramientas que le permitan vivir en mejores condiciones y empoderarlos de un lugar como sujetos políticos que se movilizan en pro de sus reivindicaciones.

\section{Referencias bibliográficas}

Alvarado, S.V. et al. (2012). La subjetividad política y la socialización política, desde las márgenes de la psicología política. Revista Latinoamericana de Ciencias Sociales, Niñez y Juventud, 10 (1), 235-256.

Aricapa, Ricardo. Las Cooperativas de Trabajo Asociado en el Sector Azucarero. Escuela Nacional Sindical, Medellín, 2006, p, 35-36

Bauman, Zygmunt (2003). Modernidad Liquida, Fondo de Cultura Económica, México.

Boletín informativo. Nuestro magazín, tele florida. Florida valle, 2008

Boltanski, Luc y Chiapelo, Eve (2002). El Nuevo Espíritu del Capitalismo,

Madrid,EdicionesAkal.

Centro de Medios Independientes, "Atrapados", Abril 10 de 2006. Tomado de:

http://colombia.indymedia.org/news/2006/04/40286.php

De La Garza Toledo, Enrique (1999) (Coordinador). Los retos teóricos de los estudios del trabajo hacia el siglo XXI. Grupo de Trabajo CLACSO. Argentina. Delgado, Álvaro. “¿Sindicatos de Paramilitares?” (2006). Tomado del blog Movimiento 13 de Abril: http:// movimiento13deabril.blogcindario.com.

de Sousa Santos, B. (2009). Una epistemología del sur: la reinvención del conocimiento y la emancipación. Ciudad de México, México: Siglo XXI Editores.

Leite, Marcia de Paula y Consuelo Iranzo (2006). “La subcontratación laboral en América Latína". En: Teorías sociales y estudios del trabajo: nuevos enfoques. De la Garza

Toledo,Enrique (coordinador). Editorial Anthropos. México DF. Pp. 268-288

McAdam, Doug; John McCarthy y Mayer Zald (1999)"Oportunidades, estructuras de movilizaciones y procesos enmarcadores: hacia una perspectiva sintética y comprada de los movimientos sociales". En: "McAdam, Doug, John McCarthy y Mayer Zald (editores). Movimientos sociales: perspectivas comparadas. Oportunidades políticas, estructuras de movilización y marcos interpretativos culturales. Editorial Istmo, pp. 2146, España-Madrid.

McAdam, Doug (1999) “Oportunidades políticas: Orígenes terminológicos, problemas actuales, futuras líneas de investigación". En: McAdam, Doug; John McCarthy y Mayer Zald (editores). Movimientos sociales: perspectivas comparadas. Oportunidades políticas, estructuras de movilización y marcos interpretativos culturales. Editorial Istmo, pp. 49-70. España-Madrid. 
Melucci, A. (1994). Asumir un compromiso: identidad y movilización en los movimientos sociales. Zona Abierta, 69, 153-180.

Olson, Mancur, "Lógica de la Acción Colectiva. Bienes públicos y la teoría de grupos", Editorial Limusa, México. 1992

Riechmann, Fernández. Jorge , Francisco Buey (1994). Redes que dan libertad: introducción a los nuevos movimientos sociales, Grupo Planeta (GBS), 1994

Rincon, Roa, Mario, Paula (2009) “Deuda social y Ambiental del Negocio de la Caña de Azucar en Colombia", Grupo Semillas, Swissaid, Sociedad Sueca para la protección de la naturaleza, Bogota Colombia

Tarrow, S. (1997). El poder en movimiento: los movimientos sociales, la acción colectiva y la política. Madrid, España: Alianza Editorial.

Tilly, C. (1993). Cambio social y revolución en Europa 1492-1992. Historia Social, 15, 71-98.

Tilly, C. (1998). Conflicto político y cambio social. Madrid, España: Trotta.

Tilly, C. (1990). Modelos y realidades de la acción colectiva popular. Zona Abierta, 54-55, 167-195.

Urrea Giraldo, Fernando (1987). “Competencia y cambio técnico en el sector azucarero en la década del 80". En Cuadernos de Agroindustria y Economía Rural \#19.

Urrea, F. \& Arango, L. G. (2000). Culturas empresariales en Colombia. En: Innovación y Cultura de las Organizaciones en Tres Regiones de Colombia. Bogotá: Colciencias y Corporación Calidad

Weber, M. (2002). Economía y sociedad. Madrid, España: Fondo de Cultura Económica.

Zibechi, R. (2006). Dispersar el poder. Los movimientos sociales como poderes antiestatales. Buenos Aires, Argentina: Tinta Limón.

Zibechi, R. (2008). Autonomía y emancipación: América Latina en movimiento. Lima, Perú: Universidad Nacional Mayor de San Marcos.

Zibechi, Raúl 2007, Dispersar el poder, Los movimientos sociales como poderes antiestatales, Ediciones desde Abajo Bogotá, D.C, Colombia.

\section{Web Grafía}

El espectador editorial (2008). El paro de los corteros de caña

Editorial. 25 Sep 2008 - 10:00 PM. Recuperado de https://www.elespectador.com/opinion/ editorial/articulo-el-paro-de-los-corteros-de-cana

Semana editorial (2008). Que no les piquen más caña. Editorial. 24 de septiembre del 200812:00 AM. Recuperado de http://www.semana.com/nacion/problemas-sociales/articulo/ que-no-piquen-mas-cana/95501-3 